\title{
The effect of date-urea blocks as supplementary feeding on growth of young camels
}

\author{
Bernard Faye $^{1,2 *}$, Gaukhar Konuspayeva ${ }^{1,4}$, Ali Almasaud ${ }^{1}$, Ahmed Alafaliq $^{3}$, Abdallah Ben Abdallah ${ }^{3}$ \\ ${ }^{1}$ FAO camel project UTF/SAU/044/SAU, Al-Kharj, Saudi Arabia, ${ }^{2}$ UMR SELMET, CIRAD-ES, Montpellier, France, ${ }^{3} F A O$ date project UTFI \\ SAU/043/SAU, Al-Ahssa, Saudi Arabia, ${ }^{4}$ Al-Farabi University, Almaty, Kazakhstan
}

\section{A B S T R A C T}

\begin{abstract}
The objective of the present trial was to evaluate the effect of incorporating date blocks in diet on growth in young camels, and in the same time, to assess the risk of toxicity due to the presence of urea in the blocks. Fifteen 3 years old camels were shared into two groups receiving in addition to alfalfa, respectively $1 \mathrm{~kg}$ of commercial concentrate or $1 \mathrm{~kg}$ of date blocks containing $50 \%$ pitted dates. Daily intake was measured, and the animals were weighed, and blood sampled every 2 weeks. No significant impact on total intake and growth throughout the experiment (135 days) was observed, but the assessment of consumption index showed a better efficiency of commercial concentrate $(1.89 \mathrm{~kg} / \mathrm{kg}$ growth) than date block $(2.33 \mathrm{~kg} / \mathrm{kg}$ growth). Uremia was higher in control group receiving the commercial concentrate, but the difference was not significant, except at the $78^{\text {th }}$ day of the experiment. No effect on glycemia, AST and ALT was observed. LDH was significantly higher at the end of the trial, but the values were in normal range. Date blocks could be used safely for a partial substitution of commercial concentrates.
\end{abstract}

Keywords: Camel; Growth; Wasted dates; Supplementation; Uremia

\section{INTRODUCTION}

In intensive camel farming system of Gulf countries, the basal diet includes mainly alfalfa and cereals which are costly in term of water requirements (Faye, 2016). Alternative diets using agricultural by-products are necessary to decrease the pressure on water resources. Two main byproducts at low price are available in Saudi Arabia, the olive cake from olive plantations and wasted dates from date palm plantations. Wasted dates could represent 10 to $40 \%$ of national production (Belal et al., 1999). However, before using those by-products at large scale, acceptance by camels and assessment of their effects of camel productivity must be investigated. A previous trial had shown that the use of olive cake could improve the fatty acid composition of the camel milk without significant negative effect on the dairy yield of the animals (Faye et al., 2013). If some trials on the use of date pits or palm date for camel feeding were published (Genin et al., 2004; Chehma et al., 2009; Mahmoud and El-Banna, 2013), at our knowledge, no data is available regarding the use of wasted dates on the growth of camel reverse to sheep growth (Rekik et al., 2008; Khezri et al., 2017) or goat milk (Al-Dobaib et al., 2009).
In palm dates plantation, the part of the production discarded from the market could be used for preparing specific feeding blocks by including, in addition, a source of protein or nitrogen.

The present study aimed to assess the use of such available by-products on growing camel and the impact of such additive on the camel growth and some blood biochemical indicators.

\section{MATERIALS AND METHOD}

\section{Blocks making}

The blocks for camel feeding were prepared in the palm date FAO project at Al-Ahsa, Saudi Arabia. Those blocks were manually pressed in cubic mold weighing approximately $2.5 \mathrm{~kg}$ after filling by a mixture of different components. The final composition of the blocks was $50 \%$ pitted dates, $5 \%$ nitrogen source (urea), $30 \%$ barley bran, $5 \%$ mineral and vitamins, $3 \%$ of binder (lime) and 7\% water. After few days, the blocks were sufficiently dry to be transported to the camel farm of the Center for Genetic improvement and Conservation at Kharj, Saudi Arabia. 
The blocks were stored in dry area and used progressively for the feeding experiment.

\section{Animals}

Fifteen young camels approximately 3 years old, belonging to the same genotype and to the same cohort (they were born at the same breeding season), were shared randomly into 2 groups of 8 and 7 animals respectively receiving daily (per animal):

- Treated group: $8 \mathrm{~kg}$ dry matter (DM) Alfalfa + $1 \mathrm{~kg}$ date-blocks with 5\% urea

- Control group: $8 \mathrm{~kg}$ DM Alfalfa $+1 \mathrm{~kg}$ of concentrates at $16 \%$ Crude Proteins (CP).

Males and females were distributed in similar proportion in the two groups ( 3 males in each group). The duration of the experiment was 135 days after 5 days adaptation.

\section{Feeding}

The quantity of alfalfa distributed was approximately calculated on the base of $2 \mathrm{~kg}$ DM $/ 100 \mathrm{~kg}$ Life Weight (LW). The quantity distributed every day was weighed as well as the refusals both for alfalfa, date blocks and commercial concentrate. The diet was distributed twice a day at morning (8:00) and evening time (16:00). Alfalfa, produced in the camel farm, was distributed in through and concentrates/ blocks in another through separately in order to measure strictly the refusals. The concentrate distributed to control group was "52052 Dairy 16 pellets" from ARASCO feed millC, Saudi Arabia, and was composed of cereals, wheat bran, soybean meal, molasses, vitamins and minerals.

\section{Weighing and sampling}

The animals were weighed in the morning before feeding at the beginning of adaptation period (d-5), at $\mathrm{d} 0, \mathrm{~d} 4$ then every 2 weeks until the end of the trial with electronic platform scale Nagata (C) for weighing animals $1 \times 2 \mathrm{~m}, 1.5$ tons max., graduation $200 \mathrm{~g}$. As the whole, 12 weighing were performed. Blood was sampled at jugular vein with vacutainer just after weighing. Blood sampling was achieved at d0, d4, d25, d38, d50, d64, d78, d93, d108. After centrifugation at $3000 \mathrm{rpm}$ for 10 minutes immediately after blood sampling, the serum was collected in tubes and frozen à $-30^{\circ} \mathrm{C}$ until biochemical analysis.

\section{Laboratory analyses}

In serum, biochemical parameters in relationships with proteo-energetic metabolism (urea, glucose) and liver or kidney damages due to potential urea toxicity (ALT, AST, LDH) were determined using bioanalyzer KENZAMAX (Biolabo (C), Les Hautes-Rives, 02160 Maizy, France). The analyses were achieved by using the available kits Biolabo for glucose (Ref. GOD-PAP/LP80209), urea colorimetric (Ref. A0010049), alanine amino-transferase (ALT) (Ref.
ALT/GPT/80127), aspartate amino-transferase (AST) (Ref. AST/GOT/80125) and lactate dehydrogenase (LDH) (Ref. LDH/92011). Each analysis was achieved in duplicate and the mean value was retained.

The date blocks, concentrate and the basal diet (Alfalfa) were analyzed at IDAC laboratory, Saudi Arabia using the references methods (AOAC, 1990). The following parameters were determined: Moisture, Crude protein (CP), Crude fiber (CF), Ether extract, Ash, Energy, NDF, ADF, sugars.

\section{Measurements}

The following measurements were achieved on the animals:

1. Intake: Total intake $=$ quantity diet distributed quantity of refusal

2. Intake/100kg LW: Mean intake between 2 weighing/ weight at the second weighing*100

3. Mean daily weight gain (DWG): (weight at d135-weight at $\mathrm{d} 0) / 135$ days

4. Total weight gain: weight at d135-weight at d0

5. Consumption index: quantity of concentrates/one kg of weight gain

\section{Statistical analyses}

Mean and standard-deviation by group was calculated each day for intake, and every 2 weeks for weight and blood biochemical parameters. A simple variance analysis (ANOVA) was used to compare the means of the intake of each component of the two diets (group control and treated). The differences between the two groups regarding the weight and biochemical parameters or total intake were tested by variance analysis on repeated measures. Correlation of Pearson was applied to test the relationships between intake/100 kg LW and blood parameters. For statistical analysis, the software XLstat (Addinsoft (C) was used.

\section{RESULTS}

\section{Nutritive value of the diet}

According to chemical composition of the 3 elements of the diet as reported in the table 1, the differences between date blocks and concentrates were marked for NDF, crude fiber, ash and ether extract (lower in date blocks), and calcium (higher in date blocks). However, no important difference was observed for crude protein and total sugar because the presence of molasse in commercial concentrate.

\section{Intake}

There was no refusal of concentrates or date blocks. One $\mathrm{kg}$ per animal was distributed and the total quantity of 
concentrates was consumed. The refusals regarding alfalfa was highly variables from day to day and the intake was consequently highly variable, especially in treated group, but on average the intake was quite similar in the two groups $(7.49 \pm 0.58$ and $7.38 \pm 0.57 \mathrm{~kg}$ in control and treated groups respectively). From the mean intake assessed between two weighing, the intake $/ 100 \mathrm{~kg} L W$ was calculated. It was $1.96 \pm$ $0.12 \mathrm{~kg} / 100 \mathrm{kgLW}$ in control group vs $1.88 \pm 0.35 \mathrm{~kg} / 100 \mathrm{~kg}$ LW in treated group. This difference was non-significant (figure 1). Falls of intake was observed on some animals at mid-November and mid-January linked to exceptional heavy rain at this period. As the whole, the mean total intake per camel in control group throughout the experiment was $1019 \mathrm{~kg}$ vs $1003 \mathrm{~kg}$ in treated group.

According to the differences in the diet composition and of the total intake, it was possible to calculate the mean intake of the different components (table 2). A high significant lower intake $(p<0.0001)$ occurred for NDF and Ether extract in treated group while sugars $(\mathrm{p}<0.05)$ and calcium $(\mathrm{p}<0.0001)$ were in lower quantity in the intake of control group.

\section{Mean daily gain weight}

The mean weight was $355 \pm 62 \mathrm{~kg}$ (control) and $391 \pm 71 \mathrm{~kg}$ (treated) at d0. On average, the mean DWG was $509 \mathrm{~g} /$ day all over the period in the control group vs $414 \mathrm{~g}$ only in

$\begin{aligned} & \text { Table 1: Composition of the elements of the diet } \\
& \text { (source: IDAC analyses) }\end{aligned}$
\begin{tabular}{lccc}
\hline Parameters & Date block & Concentrates & Alfalfa \\
\hline Moisture (\%) & 6.7 & 6.68 & 4.63 \\
Crude protein (\%) & 17.87 & 15.54 & 14.73 \\
Ether extract (\%) & 2.4 & 4.45 & 0.95 \\
Crude fiber (\%) & 5.82 & 7.82 & 31.21 \\
Ash (\%) & 5.02 & 8.0 & 10.1 \\
Energy (kcal/kg) & 2911 & 2864 & 2221 \\
ADF (\%) & 8.74 & 10.7 & 34.45 \\
NDF (\%) & 26.29 & 50.06 & 46.62 \\
Calcium (\%) & 1.6 & 0.95 & 1.4 \\
Fructose (g/100g) & 14.65 & 14.03 & 3.93 \\
Glucose (g/100g & 14.85 & 13.83 & - \\
Sucrose (g/100g & 0.43 & 0.34 & 2.42 \\
Total Sugars & 29.93 & 28.2 & 6.35 \\
\hline
\end{tabular}

\begin{tabular}{|c|c|c|c|}
\hline Parameter & Control & Treated & $P$ value \\
\hline $\mathrm{CP}(\mathrm{g})$ & 1251 & 1263 & NS \\
\hline Energy (kcal) & 19386 & 19267 & NS \\
\hline Ether extract $(\mathrm{g})$ & 115 & 94 & $<0,0001$ \\
\hline Sugars (g) & 754 & 767 & $<0,05$ \\
\hline CF (g) & 2400 & 2357 & NS \\
\hline $\operatorname{ADF}(g)$ & 2670 & 2357 & NS \\
\hline $\operatorname{NDF}(g)$ & 3969 & 2624 & $<0,0001$ \\
\hline Calcium (g) & 114 & 119 & $<0,0001$ \\
\hline
\end{tabular}

the treated group (figure 2). The weight gain was on total of $71 \mathrm{~kg}$ for control group vs $58 \mathrm{~kg}$ in treated group over 135 days. This difference was not significant.

The weight gain per $\mathrm{kg}$ of supplementation was $528 \mathrm{~g}$ in control group vs $430 \mathrm{~g}$ in treated group corresponding to consumption index of $1.89 \mathrm{~kg}$ of concentrates for $1 \mathrm{~kg}$ gain vs $2.33 \mathrm{~kg} / \mathrm{kg}$ gain weight for date blocks. The difference in DWG was not significant.

\section{Blood parameters}

There was no significant difference in the blood parameters in the both groups, even for uraemia expected to be quite higher in treated group, except on $\mathrm{d} 78$ where uraemia in treated group $(80.5 \pm 14.8 \mathrm{mg} / \mathrm{l})$ was significantly higher $(p<0.05)$ than in control one $(66.1 \pm 10.9 \mathrm{mg} / \mathrm{l})$. On average the urea concentration in serum was 67.4 (control) vs 72.3 (treated) $\mathrm{mg} / \mathrm{l}$ (figure 3a). There was a non-significant tendency of positive correlation $(\mathrm{p}=0.057)$ between DWG and uraemia in the treated group.

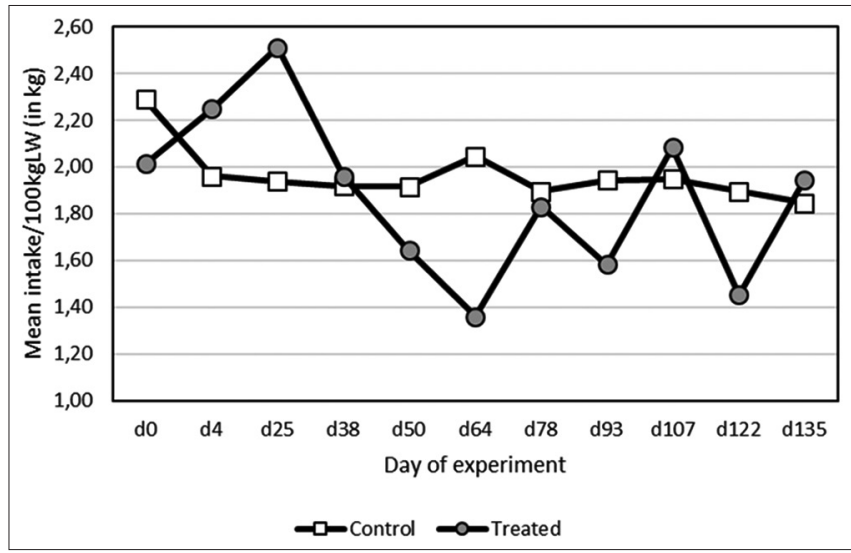

Fig 1. Changes of mean intake (kg of diet/100kg LW) in control (concentrates) and treated (date blocks) groups throughout the experiment.

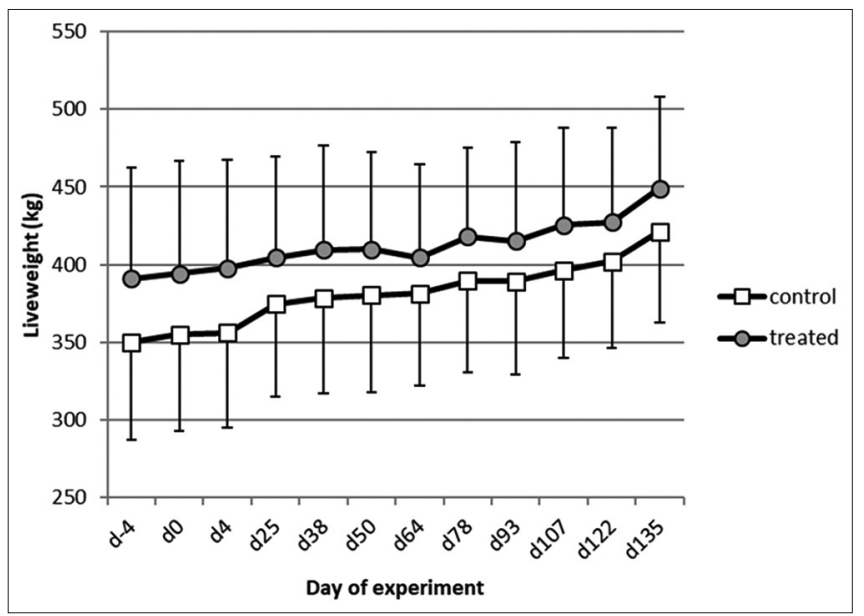

Fig 2. Changes in the weight of young camel according to the supplementation: commercial concentrates (control group) or date blocks (treated). 
The mean glycemia was the same in the two groups $(1.02 \mathrm{~g} / \mathrm{l})$ and the changes throughout the experiment were quite similar (figure $3 \mathrm{~b}$ ).

Regarding the enzymes, the mean values were respectively for control and treated groups, 19.1 and 19.7 (ALT), 146.2 and 144.7 (AST), 1293 and $1165 \mathrm{IU} / 1(\mathrm{LDH})$.

The changes all along the experiment were almost parallels for ALT and AST (figures 3c and d). However, AST was significantly lower in treated group at d38 $(p<0.001)$ and higher at $\mathrm{d} 50(\mathrm{p}<0.05)$. LDH was significantly higher also $(p<0.01)$ in control group $(1457 \pm 284 \mathrm{IU} / \mathrm{l})$ than in treated one $(1063 \pm 205 \mathrm{IU} / \mathrm{l})$ at the end of the trial (d107) (figure 4).

AST and ALT were highly correlated between them $(\mathrm{P}<0.0001)$ but not with the intake. At reverse, glycemia and uraemia were slightly negatively correlated $(\mathrm{P}<0.05)$ to intake.

\section{DISCUSSION}

Feeding supplementation with only wasted dates is not sufficient to cover the requirements in proteins and fiber, but its richness in sugars contributes to provide rapid fermentable energy. Indeed, the protein content in date fruit varied on average between 1.72 and $4.73 \mathrm{~g} / 100 \mathrm{~g}$, and the total sugars between 71.2 and $81.4 \mathrm{~g} / 100 \mathrm{~g}$ (Assirey, 2015). Moreover, it was stated that CP digestibility of date fruit was low, about 20\% only (Gihad et al., 1989). So, despite higher dry matter digestibility of date fruit in camel compare to sheep and goat (Genin et al., 2004), the enrichment of date-block in nitrogen and fiber is essential for a balanced diet. Compared to the commercial concentrate, the proposed date block had finally a comparable rate for crude protein and energy although fat content and NDF were lower due to the low content in dates (Sharifi et al., 2017). However, the components of the energy were different, a main part provided by the date blocks coming from sugars.

In ewe, the incorporation of wasted dates to replace barley had no effect on feed intake and digestible organic matter intake (Rekik et al., 2008). Also, in our trial, there was no significant effect of the substitution of commercial concentrate by date block on the total intake. However, in the experiment of Rekik et al., (2008) on ewe, a decrease in the protein digestibility was observed. Even if no significant difference was observed in the growth rate of our camels, there was a slight tendency of faster growing in the control group with a better consumption index. Indeed, DWG of the control group was $23 \%$ higher than in treated one.

Urea being the less expensive source of nitrogen, $5 \%$ urea has been added in the blocks. However, the camel is known to be very sensitive to urea intoxication (Faye et al., 1995; Kayouli et al., 1995) due to its ability to recycle nitrogen (Mousa et al., 1983). In our trial, uraemia was globally higher in the treated group. Compared to the values reported in literature which is between 50 and $400 \mathrm{mg} / 1$ with extreme means of $47 \pm 7$ (Ayoub and Saleh, 1998) and $498 \pm 55 \mathrm{mg} / \mathrm{l}$ (Osman and Al-Busadah, 2003), our results are both in the normal range.

Glycemia values also, in our trial, were quite in the normal range reported in the literature (for example Albomohsen

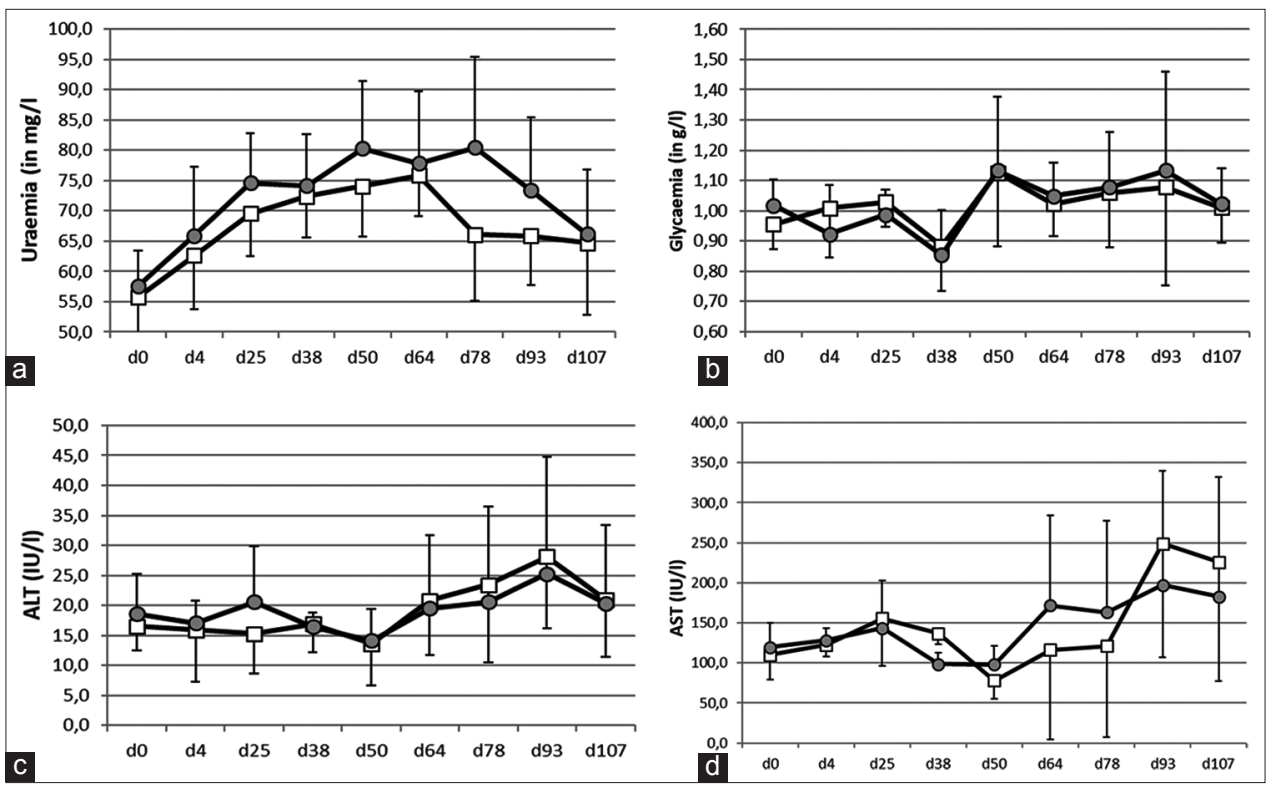

Fig 3. Changes in blood parameters in young camels receiving supplementation with concentrates (control: $\square$ ) and date blocks (treated: $\circ$ ) throughout the trial from d0 to d107: urea (a), glucose b), ALT (c) and AST (d). 


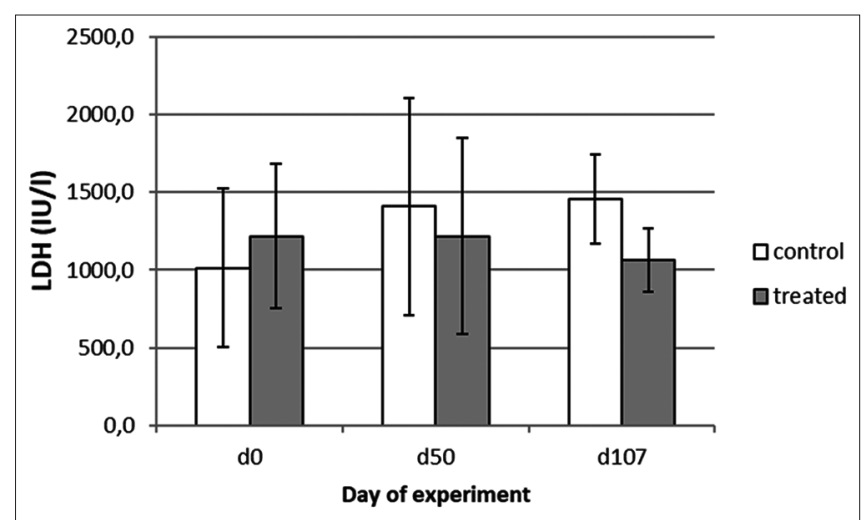

Fig 4. Changes in LDH concentration in blood serum of growing camel (control: concentrates; treated: date block) at the beginning, middle and end of the experiment.

et al., 2011; Faye et al., 2015; Sahraoui et al., 2016), glycemia in camel being comparable to monogastric values. The negative correlation with the total intake could be linked to the better use of energy in control group.

All the enzymes were also in the normal ranges. In camel, the mean usual values of serum or plasma activity for ALT are varying in the literature from 6 to $25 \mathrm{U} / 1$. It is 37 to $160 \mathrm{U} / 1$ for AST and 337 to $2620 \mathrm{U} / 1$ for LDH (for example Bengoumi, 2008; Saeed et al., 2009; Ismail et al., 2014). Some camels could have high values at the end of the experiment where the within variability was more important, but even in case of significant difference (LDH), the observed values cannot be regarded as pathologic, the maximum values being within the physiological range.

\section{CONCLUSION}

Date blocks could be used safely for young camel feeding but the impact on growth appeared lower than with concentrates even if the difference is statistically nonsignificant. However, a partial substitution to concentrates can be suggested for growing animals particularly because the production cost of date blocks $(0.5 \mathrm{USD} / \mathrm{kg})$ gives comparative advantages. In further studies, trials on lactating camels could be implemented to assess the impact on milk production and composition.

\section{ACKNOWLEDGEMENTS}

The present study was undertaken with FAO camel project UTF/SAU/044/SAU and date project UFT/ SAU/026/SAU. The authors thank FAO and Ministry of Agriculture, Saudi Arabia for allowing the conduct of the experiment. Special thanks to Dr Fuad Alzuraiq, general manager, Conservation and Genetic improvement Center; Pr Mohammed Bengoumi, technical advisor, and to Dr Abdallah Oihabi, FAO program Coordinator, for their support.

\section{REFERENCES}

Albomohsen, H., M. Mamouei, S. Tabatabaei and J. Fayazi. 2011. Metabolite composition variations of follicular fluid and blood serum in Iranian dromedary camels during the peak breeding season. J. Anim. Vet. Adv. 10: 327-331.

Al-Dobaib, S., M. Mehaia and M. Khalil. 2009. Effect of feeding discarded dates on milk yield and composition of Aradi goats. Small Rumin. Res. 81: 167-170.

Assirey, E. A. R. 2015. Nutritional composition of fruit of 10 date palm (Phoenix dactylifera L.) cultivars grown in Saudi Arabia. J. Taibah Univ. Sci. 9: 75-79.

Association of Official Analytical Chemists. 1990. Official Methods of analysis. Afr. J. Food Sci. 4: 115-119.

Ayoub, M. A., and A. A. Saleh. 1998. A comparative physiological study between camels and goats during water deprivation. In: Alhadrami, G., and M. A. Ayoub M.A (Ed.), Proc. of the Third Annual Meeting for Animal Production Under Arid Conditions. Vol. 1. Al-Ain (UAE), pp.71-87

Belal, I., M. Al-Jasser, I. Mustafa, M. Al-Dosari. 1999. Evaluation of date-feed ingredients mixes. Anim. Feed Sci. Tech. 81: 297-298.

Bengoumi, M. 2008. Tolerance study of Tiludronate in the dromedary camel. J. Camelid Sci. 1: 24-31.

Chehma, A., M. Benabdelhafid and A. Hanani. 2009. Essais d'amélioration de la valeur azotée des sous-produits du palmier dattier (pédicelles de dattes et palmes sèches) par traitement à l'ammoniac et à l'urée. Livest. Res. Rural Develop. 21.

Faye, B., M. Ratovonanahary, J. P. Chacornac and P. Soubre. 1995. Metabolic profiles and risk of diseases in camels in temperate conditions. Comp. Bioch. Physiol. 112A: 67-73.

Faye, B., G. Konuspayeva, M. Narmuratova, A. Serikbaeva, A. M. Musaad and H. Mehri. 2013. Effect of crude olive cake supplementation on camel milk production and fatty acid composition. Dairy Sci. Technol. 93: 225-239.

Faye, B., M. Bengoumi, A. Al-Masaud and G. Konuspayeva. 2015. Comparative milk and serum cholesterol content in dairy cow and camel. J. King Saud Univ. Sci. 27: 168-175.

Faye, B. 2016. The camel, new challenges for a sustainable development. Trop. Anim. Health Prod. 48: 689-692.

Genin, D., A. Kadri, T. Khorchani, K. Sakkal, F. Belgacem and M. Hamadi. 2004. Valorisation of date- palm by-products (DPBP) for livestock feeding in Southern Tunisia. I- Potentialities and traditional utilisation. In: Ben Salem H., Nefzaoui, A. and P. Morand-Fehr (Eds.), Nutrition and Feeding Strategies of Sheep and Goats Under Harsh Climates. Vol. 59. CIHEAM Options Méditerranéennes: Série A. Séminaires Méditerranéens, Zaragoza, pp. 221-226.

Gihad, E., T. El Gallad, A. Sood, H. Abou El-Nasser and M. Farid. 1989. Feed and water intake, digestibility and nitrogen utilisation by camels compared to sheep and goats fed low protein desert. Opti. Méditerranéennes Ser. A. 2: 75-81.

Ismail, A.B., A. A. Swelum, A. F. Khalaf and M. A. Abouheif. 2014. Clinical, haematological and biochemical alterations associated with an outbreak of theileriosis in dromedaries (Camelus dromedarius) in Saudi Arabia. Pak. Vet. J. 34: 209-213.

Kayouli, C., J. P. Jouany, C. Dardillat and J. L. Tisserand. 1995. Particularités physiologiques du dromadaire: Conséquences pour son alimentation. Options Méditerranéennes Sér B Etud 
Rec. 13: 143-155.

Khezri, A., O. Dayani, and R. Tahmasbi. 2017. Effect of increasing levels of wasted date palm on digestion, rumen fermentation and microbial protein synthesis in sheep. J. Anim. Physiol. Anim. Nut. 101: 53-60.

Mousa, H.M., K. E. Ali and I. D. Hume. 1983. Effects of water deprivation on urea metabolism in camels, desert sheep and desert goats fed dry desert grass. Comp. Biochem. Physiol. 74A: 715-720.

Osman, T. E. A. and K. A. Al-Busadah. 2003. Normal concentrations of twenty biochemical parameters of she-camels, cows and ewes in Saudi Arabia. Pak. J. Biol. Sci. 6: 1253-1256.

Rekik, M., N. Lassoued, H. Ben Salem and M. Mahouachi. 2008. Effects of incorporating dates in the diet on reproductive traits and digestion of prolific D'Man ewes. Anim. Feed Sci. Technol. 147: 193-205.

Saeed, A., I. A. Khan and M. M. Hussein. 2009. Change in biochemical profile of pregnant camel (Camelus dromedarius) at term. Comp. Clin. Pathol. 18: 139-143.

Sahraoui, N., A. Doudou, O. Douadji1, B. Babelhadj and J. L. Hornick. 2016. Impact of natural vegetation on some biochemical parameters of the Arabian camel (Camelus dromedarius) in Algeria. J. Camelid Sci. 9: 62-71.

Sharifi, M., M. Bashtani, A. Naserian and H. Farhangfar. 2017. Determination of chemical composition, mineral content, antioxidant capacity and rumen degradability in various varieties of wasted date palm. Italian J. Anim. Sci. 16: 507-514. 